\title{
Entre transformações e continuidades: o caso da modernização agrícola no noroeste de Minas Gerais
}

\author{
In between of change and continuity: the case of \\ agricultural modernization in northeastern Minas Gerais
}

Daniel Coelho Oliveira

Universidade Estadual de Montes Claros

\begin{abstract}
Resumo: O presente artigo busca analisar as transformações ocorridas na região Noroeste de Minas Gerais, tendo como principal referência o processo de modernização da agricultura brasileira iniciado na década de 1960. A ideia é realizar um resgate das transformações provenientes da industrialização do campo e do que se convencionou chamar de modernização conservadora da agricultura. A abordagem também apresenta as especificidades da política agrícola, suas principais ferramentas e justificativas que diferenciam essa política das demais políticas de intervenção estatal. Enfatiza-se a implementação dessas políticas no Cerrado mineiro, dando destaque para os dois programas que atingiram diretamente a área estudada, o Programa de Desenvolvimento dos Cerrados (POLOCENTRO) e o Programa de Cooperação Nipo-Brasileira para o Desenvolvimento dos Cerrados (PRODECER).
\end{abstract}

Palavras-chave: Cerrado. Espaço rural. Desenvolvimento regional.

\begin{abstract}
This article examines the changes that have occurred in the Northwestern region of Minas Gerais, mainly through the process of Brazilian agricultural modernization since the 1960s. It proposes to re-evaluate changes that have been caused by rural industrialization and the so-called conservative modernization of agriculture. The approach refers to the specific characteristics of agricultural policy, its main implementation tools and the political reasons that differentiate such interventions from other areas of government policies. It also highlights the realization of these policies in the Cerrado Mineiro, pointing specifically to two programs that tackle the study area, the Programme for Cerrado Development (POLOCENTRO) and the Nippo-Brazilian Cooperation Programme for the Development of the Brazilian Cerrado (PRODECER).
\end{abstract}

Keywords: Cerrado. Rural space. Regional development. 


\section{INTRODUÇÃO}

A intenção deste trabalho é analisar as Políticas Públicas setoriais implementadas no Cerrado mineiro, mais especificamente aquelas que, de alguma forma, atingiram direta ou indiretamente a região Noroeste $^{1}$ de Minas Gerais. As transformações ocorridas na região serão analisadas neste artigo, tendo em vista o intenso processo de modernização da agricultura brasileira ocorrido a partir de 1960.

O trabalho será dividido em duas partes e as considerações finais. A primeira seção está dividida em dois tópicos: "A 'revolução' agrícola brasileira" e "Industrialização e Modernização Conservadora". Como já indicam os subtítulos, serão discutidas as significativas transformações ocorridas na economia brasileira a partir dos anos 1960 e a expansão da fronteira agrícola no Cerrado.

$\mathrm{Na}$ segunda parte, abordaremos as especificidades da política agrícola, suas principais ferramentas e justificativas que diferenciam essa política das demais estratégias de intervenção estatal. Nessa perspectiva, será observado como essas políticas foram implantadas no Noroeste de Minas Gerais, através do processo de ocupação dos Cerrados, por meio dos vários programas de desenvolvimento implementados na região.

\section{A "REVOLUÇÃO” AGRÍCOLA BRASILEIRA}

O advento da revolução industrial e os avanços que essa acarretou possibilitaram inúmeras mudanças em diversas áreas da agricultura. Soma-se a isso o aumento da demanda por matérias-primas e alimentos

${ }^{1}$ A macrorregião de planejamento Noroeste possui atualmente 19 municípios; pode-se destacar entre eles grandes produtores agrícolas como: Unaí, Paracatu e Buritis. para uma população crescente. As transformações provocaram, em meados do século XIX, o que foi chamado de primeira Revolução Agrícola. Conforme Ehlers (1996), uma série de descobertas científicas e de avanços tecnológicos possibilitou o progressivo distanciamento da produção animal da produção vegetal.

O contínuo processo de modernização resultou na chamada Segunda Revolução Agrícola, no início do século XX, e o progresso técnico de duas Grandes Guerras Mundiais permitiu que o Brasil iniciasse, entre as décadas de 1960 e 1970, a chamada Revolução Verde. O Brasil, segundo Moreira (2000), aderiu aos pacotes tecnológicos da Revolução Verde impulsionados, principalmente, por subsídios de créditos agrícolas do Estado, que procurava estimular a grande produção agrícola nas esferas agroindustriais: empresas de maquinários, de insumos industriais para uso agrícola, tratores, herbicidas e fertilizantes químicos. O modelo de transformação impulsionado pela Revolução Verde intensificou-se no período desenvolvimentista do "milagre econômico".

O tipo de industrialização pode ser caracterizado pela mecanização e pela quimificação. Em face do pacote tecnológico de origem norte-americana aplicado em vários países do mundo no pós-guerra - pacote que combinava elementos mecânicos, químicos e sementes melhoradas, juntamente com uma larga e intensiva rede de serviços técnicos [...] (MÜLLER, 1988, p. 182).

No Brasil, o pacote de Revolução Verde foi difundido por intermédio de universidades que tinham um vínculo estreito com o sistema de educação e pesquisa dos Estados Unidos. O processo de intercâmbio foi financiado por instituições internacionais como a fundação Rockefeller e Ford, além do governo brasileiro. A ajuda do Estado ao processo de modernização da agricultura não se limitou ao incentivo e troca de 
informações: os instrumentos também se constituíram através da intervenção direta de leis e programas de subsídio.

O conjunto de medidas que, em sua concepção, pretendiam impulsionar o desenvolvimento econômico através da implementação de uma nova forma de produzir na agricultura, conservou uma estrutura agrária concentrada, apoiada na justificativa de que a grande propriedade é a mais adequada para incorporar o processo de modernização.

As inúmeras medidas governamentais voltadas à transformação do campo não estabeleceram nenhuma medida de divisão equitativa entre os setores do rural brasileiro. Os grandes agricultores foram nitidamente beneficiados em detrimento da grande parcela de pequenos agricultores. As políticas de modernização agrícola promoveram fortes subsídios à utilização de fertilizantes e defensivos, bem como a mecanização permitiu uma maior lucratividade das "culturas modernas": café, soja, trigo, entre outras. (SILVA, 1982).

\section{INDUSTRIALIZAÇÃO E MODER- NIZAÇÃO CONSERVADORA}

A década de 1950 do século XX é marcada pela contínua incorporação das atividades agrárias brasileiras à dinâmica industrial, pois faziam-se necessárias grandes transformações na estrutura de transportes, comunicação e comércio dos produtos agrícolas. “Em poucas palavras, no processo de desenvolvimento capitalista brasileiro do pós-guerra, a agricultura se converteu gradativamente num setor subordinado à indústria e por ela transformada". (SILVA, 1982, p. 43). Alterações promovidas nesse processo de acumulação capitalista foram sentidas nas atividades tradicionais do mundo rural, fenômeno que desencadeou várias implicações sociais. Uma delas foi a expropriação do campesinato, não apenas dos seus meios de produção, mas também de sua relação com o meio, de seu "saber fazer”. (PALMEIRA; LEITE, 1998).

A industrialização da agricultura designa a incorporação das atividades agrárias ao modo industrial de produzir e ao estilo empresarial de gerir a unidade econômica agrária. Ela é o resultado do consumo crescente de insumos industriais e de serviços técnicos. A industrialização da agricultura designa a integração dessa com os setores industriais e comerciais que operam com os produtos agrícolas, como agroindústria e supermercados, e cujas exigências técnicas e econômicas participam a regulação das atividades agrárias. (MÜLLER, 1988, p. 176).

Nas políticas fiscais e financeiras, a interferência do Estado "compreende um conjunto amplo de mecanismos monetáriofinanceiros e de incentivos fiscais, que estimulam, compensam e financiam a aplicação de capitais privados nas atividades rurais." (DELGADO, 1985, p. 45). Faz parte desse conjunto o Sistema Nacional de Crédito Rural (SNCR), o qual universalizou e expandiu o crédito antes limitado a setores específicos (Institutos do Café e do Álcool e Açúcar). O novo sistema de crédito para agricultura estabeleceu taxas de juros subsidiadas, prazos extensos e longas carências para pagamento.

Algumas políticas adotadas pelo Estado serviram para aumentar ainda mais a disparidade entre regiões econômicas e grupos sociais. Segundo Delgado (1985), milhões de estabelecimentos rurais não foram incorporados ao processo de modernização. Fazem parte desse grupo produtores periféricos não integrados ao Complexo Agroindustrial (CAI), desprivilegiados pelo crédito subsidiado, os quais, em última instância, serão expropriados de suas terras e farão parte de uma massa de assalariados ou 
desempregados marginais ao sistema moderno de produção agrícola.

A região Centro-Sul foi um dos espaços privilegiados dessas transformações, onde se concentrou maior parte dos recursos estatais investidos no projeto de modernização da agricultura. No Nordeste, ${ }^{2}$ Norte e nas “Novas Fronteiras, prevaleceram processos heterogêneos e uma estrutura agrária concentradora". (DELGADO, 1985).

Conforme Cleps Junior et al. (2005), com o resultado do modelo de agricultura implantada, houve aumento significativo nos indicadores técnicos de modernização agrícola, elevação e diversificação da produção e alteração no padrão técnico do setor rural. Nesse cenário, a implantação de políticas públicas para subsidiar a compra de tecnologias externas foi essencial para o desenvolvimento da agricultura empresarial. Contudo, as oligarquias rurais ligadas à grande propriedade territorial e ao capital comercial sustentaram concentração fundiária, não possibilitando o rompimento da velha estrutura agrária. Ao contrário, velhas desigualdades foram reafirmadas, consolidadas e expandidas.

[...] a estratégia agropecuária articulada a partir de meados da década de 1960 contém, simultaneamente, certos fatores de modernização e conservadorismo que se enunciam na caracterização dos subsetores "moderno" e "arcaico" [...] A reprodução dessa estrutura manifesta a síntese contraditória dos elementos constitutivos e se mostra de maneira mais crua e violenta na sua "frente de expansão", genericamente aqui caracterizados pelo subsetor "fronteira agrícola". (DELGADO, 1985, p. 59).

${ }^{2}$ Foram realizados grandes investimentos financeiros no setor agrícola do Nordeste do Brasil através da Superintendência de Desenvolvimento do Nordeste (SUDENE). Os recursos foram destinados para um número limitado de agricultores, demonstrando uma clara conciliação entre interesses clientelistas das oligarquias regionais e os interesses modernos dos empresários do Sudeste. (MARTINS, 1999). Posteriormente, foi criada a Superintendência de Desenvolvimento da Amazônia (SUDAM), com consequências semelhantes.
Delgado (1985) observa que os traços da modernização conservadora são mais evidentes nas chamadas fronteiras agrícolas. Nessas regiões, notam-se processos modernizantes, incentivados pelo Estado, conciliados com uma base de interesses oligárquicos locais; uma aliança política conservadora, expressa principalmente pela grande propriedade rural.

[...] a experiência desses últimos vinte anos revelou à sociedade que o estilo de industrialização liberal, respaldado no autoritarismo político que não admitiu debate algum sobre fins alternativos a uma modernização desejada por muitos, não funcionou indutivamente para os pequenos proprietários, arrendatários, parceiros e ocupantes, uma vez que não os incorporou à modernização, chegando até a aumentar a pobreza. Não admitir isso seria elidir a realidade parcial, majoritária, porém, criada pela constituição do setor dinâmico da agricultura. (MÜLLER, 1988, p. 181).

A expansão capitalista no campo faz parte de um processo maior de expansão do capital de revolução das relações de produção nesse setor, entretanto, essas relações não se alteram por inteiro, o capital não realizou uma expropriação completa. A "agricultura brasileira espelha avanços e recuos de uma lenta e, por isso mesmo, dolorosa modernização em alguns setores específicos, modernização essa em sua maior parte sustentada pelos subsídios estatais". (SILVA, 1982, p. 33).

Após o resgate do processo de modernização ocorrido na agricultura brasileira, apresenta-se, a seguir, uma caracterização sobre políticas públicas para o espaço rural. Pretende-se abordar, de forma específica, as transformações em um dos espaços de expansão da chamada fronteira agrícola, a região dos Cerrados no Noroeste mineiro. 


\section{POLÍTICAS PÚBLICAS PARA O ESPAÇO RURAL E O CASO DO NOROESTE DE MINAS GERAIS}

Para caracterizar a implantação da política agrícola no Noroeste de Minas Gerais, é preciso definir o que é propriamente uma política agrícola, de forma que seja possível entender a participação dessa política dentro de um corpo de políticas estatais. Será preciso, também, apresentar quais são as especificidades dessa política setorial, se existem demandas diferenciadas do setor em relação aos demais.

Várias são as características peculiares da política agrícola. ${ }^{3}$ A primeira delas compreende a sazonalidade, os fatores climáticos, ambientais e os ciclos biológicos das plantas e animais. Uma das formas de enfrentar a sazonalidade é através das inovações tecnológicas: encurta-se o tempo de crescimento dos animais, desenvolvem-se plantas mais adaptadas às condições climáticas e ambientais. "Essa sazonalidade se reflete em uma acentuada rigidez da produção agropecuária, seja para responder às mudanças nas condições de mercado seja para organizar seus fluxos financeiros". (BUAINAIN, 1997, p. 9).

Decorre dessa característica a necessidade de se implantarem políticas diferenciadas de crédito rural, que possibilitem aos produtores rurais recursos que atendam às especificidades do setor.

O documento Organização das Nações Unidas para Agricultura e Alimentação (FAO/ONU 1995) demonstra que toda política setorial tem um conteúdo implícito e outro explícito. O conteúdo implícito se relaciona com os efeitos indiretos da política macroeconômica sobre o setor. Já o conteúdo explícito se relaciona com um

\footnotetext{
${ }^{3}$ Lamounier (1994) define política agrícola como um conjunto de ações do governo dirigidas ao setor agropecuário, cujos objetivos são: reduzir custos através do investimento em infraestrutura e pesquisa; estabilizar a renda do produtor; e prover crédito. O autor também classifica três distintas categorias de políticas públicas: distributiva, regulatória ou redistribuitiva.
}

conjunto de medidas e intervenções do Estado objetivamente no setor. O mesmo documento da FAO/ONU destaca a importância de alguns instrumentos econômicos e setoriais no setor agrícola.

Os principais instrumentos econômicos:

a) política monetária: define as margens de manobra do instrumento setorial, crédito rural;

b) política fiscal: política que interfere sobre o volume de gastos públicos com a política setorial agrícola;

c) política cambial e comercial: determina os preços relativos dos bens agrícolas em relação aos bens industriais e define a margem de lucro dos produtos exportáveis.

Os principais instrumentos setoriais:

a) política de preços: define estímulos à produção associados a um certo produto;

b) política de comercialização: estabelece as condições para que os produtos cheguem ao consumidor final;

c) política de preços de insumos agrícolas: fomenta a opção por um certo pacote tecnológico e de insumos;

d) política de crédito: define as condições de financiamento da produção;

e) política de comércio exterior: regula as exportações agrícolas;

f) política de gasto público: determina o volume de fluxos fiscais direcionados ao setor, na forma de programas de pesquisas, capacitação, infraestrutura e apoios complementares.

Várias características diferem o setor agrícola do industrial, ${ }^{4}$ além dos ciclos biológicos, climáticos e das demais

\footnotetext{
${ }^{4}$ A demanda por produtos agrícolas possui diferenças em relação aos produtos industriais: "à medida que a renda nacional cresce a demanda agregada por produtos agrícolas também cresce, mas numa proporção menor do que o aumento da renda [...] no caso dos produtos industriais, por contraste, a demanda agregada aumenta consideravelmente com a elevação da renda nacional, numa proporção superior a essa, indicando que a demanda por produtos industriais é bastante elástica em relação à renda". (DELGADO, 2001, p. 18).
} 
sazonalidades: há na agricultura uma maior distância entre a decisão de produzir, o processo produtivo e a obtenção dos resultados. Tais características fazem com que a liquidez ${ }^{5}$ financeira do setor agrícola seja menor do que a do setor industrial.

Los gobiernos se ven obligados a intervenir para corregir los términos de intercambio y sustentar los precios y la rentabilidad del sector agrícola. Esas políticas de apoyo a la agricultura son, en general, importantes para dar a los productores rurales un contrapeso frente al poder de mercado prevaleciente en el sector industrial y, así, para proteger los ingresos rurales. (FAO/ ONU, 1995, p. 68).

A corrente liberal da economia defende que a melhor política pública é simplesmente deixar que o mercado funcione livremente, sem o auxilio do Estado. Mas, em praticamente todos os países do mundo, os governos têm implementado políticas agrícolas fortes. (BUAINAIN, 1997).

Todos os governos, de uma forma ou de outra, desenvolvem uma política diferenciada para a agricultura, porém, há diferenças consideráveis entre as inúmeras práticas de planificação agrícola. Existem diferenças entre políticas de países "desenvolvidos" e "subdesenvolvidos", entre países predominantemente agrícolas e países majoritariamente industriais.

No Brasil, as políticas públicas para a agricultura podem ser evidenciadas na expansão da "fronteira agrícola", que aconteceu de forma intensiva na região dos Cerrados, classificada como a maior fronteira do mundo, região de inúmeros projetos governamentais.

Os Cerrados são vistos como um dos biomas mais importantes do planeta, uma

${ }^{5}$ Segundo Buainain (1997, p. 9), “Enquanto na indústria é em geral possível utilizar as receitas correntes para cobrir pelo menos parte dos gastos correntes, na agricultura despesas e receitas se realizam em períodos diferentes: ao longo de vários meses o agricultor deve cobrir os gastos com a preparação do solo, plantio, mão de obra, serviços etc". vez que cobrem praticamente um quarto do território brasileiro, ocupando uma área equivalente à Europa Ocidental, e concentram nada menos que um terço da biodiversidade nacional e $5 \%$ da flora e da fauna mundial. A região está localizada, basicamente, no Planalto Central do Brasil e é o segundo maior bioma do país em área.

Contudo, historicamente, ela ocupa um lugar de desprezo em relação a outras paisagens brasileiras. Segundo Ribeiro (1997), alguns viajantes estrangeiros ${ }^{6}$ demonstraram deslumbramento pela densa Mata Atlântica e uma visão depreciativa das árvores "retorcidas" e "esparsas" características da maior parte do Cerrado. Em muitos relatos, observa-se que o Cerrado não era considerado como um sistema próprio, sua biodiversidade era vista como sendo de segunda categoria.

Foi a partir da visão desenvolvimentista do governo militar brasileiro que, efetivamente, planejou-se ocupar esse "vazio" demográfico e econômico. Os solos "estéreis" não seriam mais um empecilho para a expansão da agricultura, pois sua topografia favorecia a expansão da agricultura moderna (DAYRELL, 2000). Estava aberta uma nova fronteira ${ }^{7}$ agrícola.

\footnotetext{
${ }^{6}$ Vários viajantes estrangeiros tiveram contato com o Cerrado brasileiro a partir do século XIX: Whilhelm Ludwig (1811-1821), Auguste P. de Saint-Hilaire (1816-1821), Johann B. von Spix (1781- 1826), Karl Friedrich P. von Martius (1794-1868) entre muitos outros. (RIBEIRO, 1997).

7 Neste trabalho, "fronteira" se aproxima da visão de Martins (1993, p. 162): "é um espaço social e um tempo histórico, nos quais diferentes e os desiguais se encontram e se desencontram em constantes relações de conflito e tensão, e nas quais o outro é percebido como alguém inferior, selvagem e que pode e é dominado e explorado [...] o aparentemente novo da fronteira é na verdade, expressão de uma complicada combinação de tempos históricos em processos sociais que recriam formas arcaicas de dominação [...]. As formas arcaicas ganham vida e consistência por meio de cenários de modernização e, concretamente, pela forma de dominação da acumulação capitalista, racional e moderna."
} 


\section{OCUPAÇÃO DO NOROESTE DE MINAS GERAIS}

No século XVII, a região Noroeste recebeu dois importantes fluxos migratórios. $\mathrm{O}$ primeiro fluxo era composto por vaqueiros, os quais conduziam gado vindo das províncias de Pernambuco e Bahia, formando fazendas de criação que, posteriormente, deram origem a vilas e arraiais. O segundo, vindo do Sul, foi representado pelas expedições dos bandeirantes paulistas. A partir dessa origem, a região se caracterizou por uma economia agro-pastoril, uma sociedade estratificada com predomínio do compadrio e uma organização política baseada na ordem privada. Por vários séculos, a região manteve-se isolada do restante do país, em um ritmo de crescimento lento e retardatário. (MATA-MACHADO, 1991).

Somente em meados do século passado ocorreram grandes transformações na região: a construção da hidrelétrica de Três Marias, em 1958, a implantação da BR-040 ligando a região Noroeste com o Distrito Federal e com Belo Horizonte e a transferência da capital do Rio de Janeiro para Brasília, fatos que provocaram alterações significativas no cenário regional.

A região era vista como possuidora de todas as características que definem uma área como fronteira agrícola: "vazio" demográfico, organização social e econômica arcaica, distante da capital do estado, e insignificante em termos de contribuição para o desenvolvimento econômico do país, uma frente de expansão perfeita para a "moderna" agricultura capitalizada. (TORRES; FERREIRA NETO, 2002).

A ação governamental foi a grande fomentadora da expansão agrícola "moderna" na região Noroeste. A partir do Plano Nacional de Desenvolvimento (PND), previa-se a criação de diversos programas de desenvolvimento regional. Na Tabela 1 , mostram-se a relação de alguns dos programas criados entre a década de 1970 e 1990, seus respectivos custos de implantação, área ocupada, bem como os estados que receberam os projetos.

Tabela 1: Programas governamentais de desenvolvimento agrícola do Cerrado

\begin{tabular}{c|c|c|c|c}
\hline Programa & Criação & $\begin{array}{c}\text { Custo (US\$ } \\
\text { milhões) }\end{array}$ & Área (ha) & Estados \\
\hline PCI & 1972 & 32 & 111.025 & MG \\
\hline PADAP & 1973 & 200 & 60.000 & MG \\
\hline POLOCENTRO & 1975 & 868 & 3.000 .000 & MG, MS, MT, GO \\
\hline PRODECER I & 1979 & 94 & 60.000 & MG \\
\hline PRODECER II & 1985 & 409 & 180.000 & MG, MS, MT, GO, BA \\
\hline PRODECER III & 1994 & 66 & 80.000 & MA, TO \\
\hline TOTAL & & 1.669 & 3.491 .025 &
\end{tabular}

Fonte: IBASE, JICA e FUNDAÇÃO JOÃO PINHEIRO apud RIBEIRO (2005, p. 174)

A década de 1970 marca o início dos grandes projetos de desenvolvimento nos Cerrados. A primeira experiência piloto ocorreu com a criação do Programa de Crédito Integrado e Incorporação dos Cerrados - PCI, criado no início da década de 1970 pelo Banco de Desenvolvimento de Minas Gerais - BDMG, com recursos do Banco Central e Banco Mundial. Além da região Noroeste de Minas, outras regiões faziam parte do programa: Triângulo Mineiro, Alto Paranaíba e Alto e Médio São Francisco. O sucesso do PCI incentivou a criação de novos programas. Outro importante programa foi criado em 1973, com a assinatura do acordo entre o governo de Minas Gerais e a Cooperativa Agrícola de Cotia (CAC). Foram desapropriados 60.000 hectares nos municípios de São Gotardo, Ibiá, Rio Paranaíba e Campos Altos para a criação do Programa de Assentamento Dirigido do Alto Paranaíba (PADAP). A estratégia do programa era criar cooperativas de colonos com concentração espacial das atividades agrícolas. (RIBEIRO, 2005). 


\section{DO POLOCENTRO AO PRODECER}

Em 1975 foi criado o Programa de Desenvolvimento dos Cerrados (POLOCENTRO), um ambicioso projeto de expansão da área plantada do Cerrado. Através destes programas do POLOCENTRO, de acordo com Marouelli (2003), procurou-se transformar a agricultura de subsistência em uma agricultura empresarial, usando práticas agrícolas modernas e a integração com o mercado, através de assistência técnica, apoio financeiro e de infraestrutura. ${ }^{8}$ A estratégia do Programa consistia na implantação dos pólos de desenvolvimento, localizados de modo a promover a difusão da tecnologia agrícola para toda a extensão dos Cerrados. A sua ação foi desenvolvida por meio da integração entre a pesquisa, assistência técnica e crédito rural orientado.

O programa atingiu uma área de três milhões de hectares do Cerrado em 202 municípios dos Estados de Minas Gerais, Goiás, Mato Grosso e Mato Grosso do Sul. Foram financiados lavouras, pastagens e reflorestamento. Dos recursos executados no programa, cerca de $75 \%$ eram destinados a programas especiais de crédito; o restante, à pesquisa agropecuária, assistência técnica, armazenamento, transportes e eletrificação rural. As linhas de crédito do POLOCENTRO ofereciam possibilidades mais amplas do que as demais linhas de crédito agrícola disponíveis no mercado. Segundo Alvares da Silva (1989, apud Ribeiro, 2005), havia vários diferenciais importantes:

a) investimento básico destinado ao preparo inicial dos Cerrados, incluindo calagem e obras de proteção do solo;

${ }^{8}$ O POLOCENTRO, até 1978, investiu18,5\% do seu orçamento em armazenamento (Armazéns com capacidade de receber 434 mil toneladas), construiu três mil quilômetros de estrada e dois quilômetros de linhas de eletrificação. (RIBEIRO, 2005). b) investimentos complementares normais, necessários à continuidade do aproveitamento das terras;

c) patrulhas mecanizadas;

d) custeio das atividades agropecuárias e de patrulhas mecanizadas;

e) fertilizantes para a adubação intensiva.

Segundo França (1984), o resultado do POLOCENTRO não foi significativo em termos de incrementação da produção agrícola. ${ }^{9} \mathrm{O}$ relativo fracasso desse programa e a necessidade de recursos financeiros para continuar a intervenção nos Cerrados viabilizaram um acordo entre o governo brasileiro e o japonês para a implantação, em 1978, do PRODECER, programa de colonização dirigida, implementado pela Companhia de Promoção Agrícola (CAMPO) ${ }^{10}$ responsável pela execução do acordo entre os dois países.

O PRODECER I foi todo implantado no estado de Minas Gerais, onde se organizaram três grandes projetos de colonização nos municípios de Iraí de Minas, Coromandel e Paracatu. Este foi o primeiro município da região Noroeste de Minas a receber um núcleo de colonização agrícola dos grandes projetos. O PRODECER II implantou 15 núcleos de colonização nos estados da Bahia, Goiás, Manto Grosso, Mato Grosso do Sul e Minas Gerais; sendo que, nesta segunda etapa, foi implantado um núcleo no município de Buritis, também pertencente à região Noroeste de Minas Gerais. A terceira fase, mais recente, está sendo implantada

\footnotetext{
${ }^{9}$ Ribeiro (2005) também chega a uma conclusão semelhante e aponta como um dos problemas o elevado grau de dispersão de suas ações, o que influenciou o PRODECER a utilizar a estratégia de colonização dirigida, nos mesmos moldes do PADAP. 10 O programa foi financiado pelos Governos do Brasil, do Japão e bancos privados japoneses. A CAMPO, empresa de capital binacional, foi criada para este fim, com $51 \%$ das ações pertencentes ao lado brasileiro, representado pela BRASAGRO, e $49 \%$ do lado japonês, representado pela JADECO. (MAROUELLI, 2003).
} 
nos estados do Maranhão e Tocantins. (RIBEIRO, 2005).

O PRODECER tinha objetivos semelhantes ao POLOCENTRO, como ocupar áreas até então não exploradas com técnicas modernas de produção agrícola e alta utilização de insumos, mas o subsídio financeiro foi muito maior no PRODECER, devido, principalmente, ao montante de capital investido pelos japoneses. Outra importante diferença deste programa em relação ao POLOCENTRO deve-se ao fato de que os investimentos eram focalizados em núcleos de colonização de médio e grande porte.

As condições de financiamento dos programas de desenvolvimento do Cerrado eram subsidiadas. Segundo Ribeiro (2005), o POLOCENTRO e o PRODECER I apresentavam propostas de crédito rural melhores do que as adotadas pelo Banco do Brasil, principalmente no que se refere à linha de crédito para investimento, condição que influenciou decisivamente a "modernização" de um grande número de produtores na região. A maior parte dos beneficiados pelos programas era composta por grandes e médios produtores. ${ }^{11}$ (Tabela 2). Assim como ocorreu nas demais regiões, o crédito direcionado aos produtores do Cerrado era seletivo e excedente.

Tabela 2: Distribuição dos créditos do POLOCENTRO e porcentagem de recursos (1975-1982)

\begin{tabular}{c|c|c}
\hline Estrato de área (Hectare) & No de projetos (\%) $^{\circ}$ & Recursos (\%) \\
\hline menos de 100 & 2,2 & 0,38 \\
\hline De 100 a 200 & 7,1 & 1,78 \\
\hline De 200 a 500 & 30,7 & 21,39 \\
\hline mais de 500 & 60 & 76,45 \\
\hline
\end{tabular}

Fonte: FUNDAÇÃO JOÃO PINHEIRO (1985), apud RIBEIRO (2005, p. 179)

Sabe-se que, historicamente, o Brasil apresenta forte concentração fundiária.

\footnotetext{
${ }^{11}$ Os lotes destinados aos colonos do PADAP e PRODECER
} possuíam áreas entre 350 e 450 hectares.
Conforme Prado Junior (1987) e Martins (1981), a iniquidade característica do período colonial encontra fortes reflexos na contemporaneidade. A Tabela 2 demonstra que a concentração fundiária está diretamente relacionada com a destinação de recursos financeiros para o meio rural. Os grandes projetos de desenvolvimento, como é o caso do POLOCENTRO, foram extremamente seletivos. É notório que os $0,38 \%$ dos recursos para propriedade com menos de 100 hectares revelam que pequenas propriedades não se enquadrariam no modelo de desenvolvimento proposto naquele momento histórico. Ao contrário, as propriedades com mais de 500 hectares absorviam mais de três terços dos recursos. Ou seja, grande propriedade e acesso a recursos é uma relação que não perdeu sentido com a "modernização" do Brasil.

\section{CONSIDERAÇÕES FINAIS}

A ação do Estado no Noroeste favoreceu alguns setores, propiciando a incrementação de uma pauta produtiva especializada destinada ao processamento industrial - uma nítida inserção da agricultura no complexo agroindustrial do país. O Cerrado foi sendo colonizado por empresas tipicamente capitalistas. Segundo França (1984), a ação dessas empresas na região transformou a estrutura produtiva existente, provocando a eliminação de um grande número de unidades de exploração familiar. Inicialmente, a implantação dos programas de colonização agrícola no Cerrado mineiro melhorou relativamente a distribuição de terra na região, mas, com o passar do tempo, os agricultores mais capitalizados adquiriram novas áreas de produtores menores e descapitalizados, provocando uma maior concentração fundiária.

Para os trabalhadores, o processo de modernização agrícola na região Noroeste 
significou um brutal deslocamento social, provocado, principalmente, pela mudança na pauta produtiva. Agregados, posseiros e meeiros experimentaram a modernização como uma ruptura no seu modo de viver. A precarização do acesso à terra, a contratação temporária e precária de bóias-frias substituíram famílias inteiras que trabalhavam e residiam por várias gerações na região. Estes fenômenos de desagregação socioeconômica de populações tradicionais mostram a fragilidade do modelo de desenvolvimento adotado e abrem, assim, um precedente para questionarmos o desempenho econômico da agricultura na região denominada de "celeiro" de Minas Gerais. (TORRES; FERREIRA NETO, 2002).

Pode-se considerar que a agricultura brasileira experimentou um processo mais amplo de transformação, que só atingiu o Noroeste mineiro em meados dos anos 1970. As transformações ocorridas no cenário regional são marcadas pela especificidade dos vários planos de desenvolvimento como o POLOCENTRO e o PRODECER que transformaram a paisagem, a forma de produzir e as relações sociais e de trabalho na região.

\section{REFERÊNCIAS}

BUAINAIN, Antonio Marcio. Trajetória recente da política agrícola brasileira. Campinas: Projeto FAO/036/BRA, 1997.

DAYRELL, Carlos Alberto. Os geraizeiros descem a serra ou a agricultura de quem não aparece nos relatórios do agrobuisiness. In: DAYRELL, C. A.; LUZ, Claudia (Org.). Cerrado e desenvolvimento. Montes Claros: CAA-NM, 2000.

DELGADO, Guilherme. Capital financeiro e agricultura no Brasil. São Paulo: Unicamp, Ícone,1985.

DELGADO, Nelson. Política econômica, ajuste externo e agricultura. In: LEITE, S. (Org.). Políticas públicas e agricultura no Brasil. Porto Alegre: Ed. da Universidade, 2001.

DUARTE, Laura Maria Goulart; THEODORO, Suzi Huff, (Orgs.). Dilemas do cerrado: entre o ecologicamente (in)correto e o socialmente (in)justo. Rio de Janeiro, Garamond, 2002.

EHLERS, E. Agricultura sustentável: origens e perspectivas de um novo paradigma. São Paulo: Livros da terra, 1996.

FAO/ONU. Macroeconomia y políticas agricolas: una guía metodológica. Roma: FAO, 1995.

FRANÇA, Múcio. O cerrado e a evolução recente da agricultura capitalista: a experiência de Minas Gerais. 1984. Dissertação (Mestrado em Planejamento Regional). Belo Horizonte: UFMG, Centro de Desenvolvimento e Planejamento Regional.

LAMOUNIER, B. (Coord.). Determinantes políticos da política agrícola: um estudo de atores, demandas e mecanismos de decisão. Brasília: IPEA, 1994.

LEITE, S. Padrão de financiamento, setor público e agricultura no Brasil. In: LEITE, S. (Org.). Políticas públicas e agricultura no Brasil. Porto Alegre: Ed. da Universidade, 2001.

CLEPS JUNIOR, João, et al. Estado e capital: as conseqüências socioambientais do uso intensivo dos recursos naturais do município de Buritizeiro (MG). In: CONGRESSO DA SOCIEDADE BRASILEIRA DE ECONOMIA E SOCIOLOGIA RURAL, 43., 2005, Ribeirão Preto - SP, Anais... Ribeirão Preto, 2005. Disponível em: <http:/ / www.sober.org.br/ palestra/2/1017.pdf.> Acesso: 21 ago. 2010.

MAROUELLI, Rodrigo Pedrosa. O desenvolvimento sustentável da agricultura no cerrado brasileiro. Monografia (Especialização em Gestão sustentável da agricultura irrigada) 2003. Instituto interamericano de cooperação para a agricultura (IICA), Brasília - DF.

MATA-MACHADO, Bernardo Novaes da. História do sertão noroeste de Minas Gerais. Belo Horizonte: Imprensa Oficial, 1991.

MOREIRA, Roberto José. Críticas ambientalistas à revolução verde. Estudos Sociedade e Agricultura. v. 15, p. 39-52, 2000.

MARTINS, José de Souza. A chegada do estranho. São Paulo: Hucitec, 1993.

O poder do atraso: ensaios de sociologia da história lenta. São Paulo: Hucitec, 1999. 
Os camponeses e a política no Brasil.

Petrópolis: Vozes, 1981.

MÜLLER, Geraldo. Ambivalência da modernização agrária. Revista novos estudos CEBRAP, n. 21, p. 168-184, 1988.

PALMEIRA, Moacir; LEITE, Sérgio. Debates econômicos, processos sociais e lutas políticas. In: Costa, L. F.; Santos, R. (Orgs.). Política e reforma agrária. Rio de Janeiro: Mauad, 1998.

PRADO JÚNIOR, Caio. Formação do Brasil Contemporâneo. São Paulo, Brasiliense, 1987.

RIBEIRO, Ricardo Ferreira. O sertão espiado de fora: os viajantes estrangeiros descobrem o cerrado mineiro na primeira metade do século XIX. Rio de Janeiro: CPDA, 1997.

Da "largueza" ao "cercamento". Um balanço dos programas de desenvolvimento do cerrado. In: ZHOURI, Andréa (Org). A insustentável leveza da política ambiental: desenvolvimento e conflitos socioambientais. Belo Horizonte: Autêntica, 2005.

SILVA, José Graziano. A modernização dolorosa: estruturas agrárias, fronteiras agrícolas e trabalhadores rurais no Brasil. Rio de Janeiro: Zahar, 1982.

TORRES, André Luiz; FERREIRA NETO José Ambrósio. Análise do processo de desenvolvimento da região noroeste de Minas Gerais. In: CONGRESSO BRASILEIRO DE ECONOMIA E SOCIOLOGIA RURAL, 37, 2002, Foz do Iguaçu, Anais...

Recebido em 08/06/10

Aceito para publicação em 14/09/10 


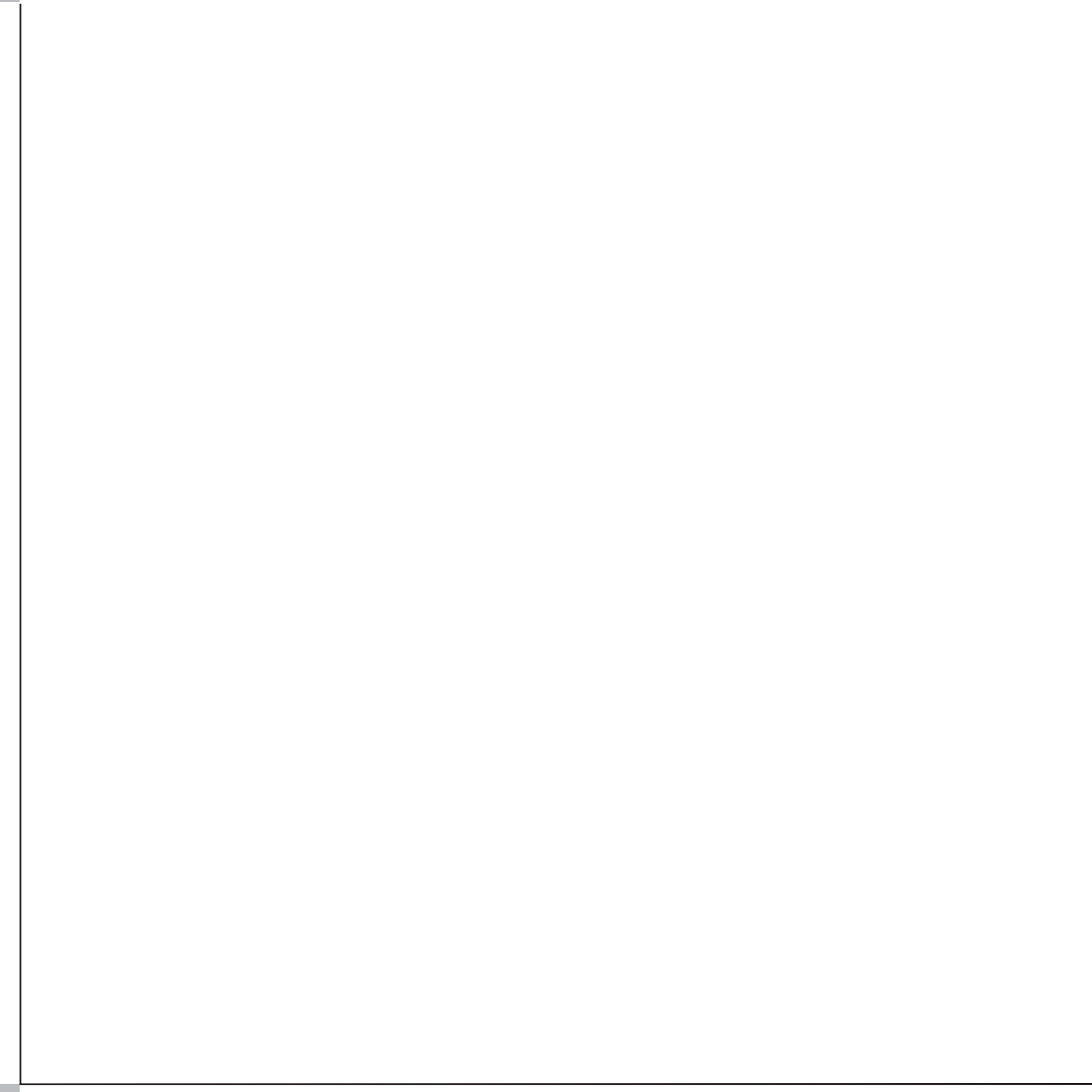

